\title{
Could the IMS Infrasound Stations Support a Global Network of Small Aperture Seismic Arrays?
}

\author{
Steven J. Gibbons ${ }^{1}$, Tormod Kværna, and Svein Mykkeltveit \\ INTRODUCTION
}

The monitoring of earthquakes and underground explosions worldwide is performed using networks of seismic stations. The vast majority of these stations consist of three mutually orthogonal sensors, one vertical and two horizontal, at a single site. Seismic signals are detected on individual stations and events are then defined and located by associating the signals recorded on many different stations. Some networks are global (see e.g. Romanowicz and Giardini, 2001, Ammon et al., 2010) while there are increasingly many national and regional networks which, with increasing available computational power and decreasing data transmission and storage costs, are continually becoming denser. This is particularly the case for highly populated regions with significant and destructive seismicity, such as Japan (e.g. Okada et al., 2004). Networks such as the USArray (Levander et al., 1999) and GLISN (Clinton et al., 2014) can comprise both permanent and temporary stations, covering vast regions, usually over a limited time-span, to glean information about structure and geophysical processes. It is, however, still the case that large regions of Earth have very poor coverage of permanent seismic stations.

Seismic arrays are a special class of seismic station consisting of seismometers at numerous closelyspaced sites (usually within an aperture of a few kilometers) such that signal detection and parameter estimation are greatly enhanced by coherently processing the waveforms at the different sites. Progress in seismic array technology was driven largely by the need to monitor underground nuclear weapons testing (e.g. Douglas, 2002) since the events being monitored by any one country were taking place in the territory of another country and it became imperative to be able to detect and identify correctly a weak seismic signal generated by a remote explosion. With the opening for signing of the Comprehensive Nuclear-Test-Ban Treaty (CTBT) in 1996 (see Dahlman et al., 2009, 2011), many of the seismic arrays operated by the various nation states were assimilated into the global seismic network of the International Monitoring System (IMS). The locations of all the existing arrays, together with the 3-component (3-C) stations of the so-called primary seismic network, are displayed in Figure 1. Also displayed in Figure 1 are the locations of the stations of the global infrasound network of the IMS, intended primarily to detect low frequency sound waves generated by atmospheric nuclear tests. Whereas the seismic component of the IMS was determined to a significant extent by existing infrastructure, and a political need for a balanced monitoring capability for existing nuclear test sites, the infrasound network was built from scratch with far fewer constraints.

All infrasound stations in the IMS are arrays, and necessarily so. The most important parameter associated with a seismic signal is its arrival time, and this attribute can frequently be obtained with great accuracy from a single-site station; the backazimuth of seismic signals is usually of secondary importance. The opposite is true of infrasound signals. The infrasound signal onset time is usually difficult to measure and is not predicted with great accuracy given a hypothetical source; the

\footnotetext{
${ }^{1}$ NORSAR, Kjeller, Norway.
} 
backazimuth of an infrasound signal is arguably of far greater importance in most cases of acoustic event location. Whereas seismic arrivals are transient and typically detected by a sudden increase of energy in a given frequency band, infrasound signals are typically very emergent, of long duration, and often only distinguishable from the background noise due to a significant similarity between the waveforms on neighboring sensors. For these reasons, while there was international consensus that 3-component stations would suffice for completing the seismic network in parts of the world with a presumed low risk of potential treaty violations, it was acknowledged that the infrasound stations in these parts of the world would need to be arrays. The IMS infrasound arrays are distributed remarkably uniformly over the globe and provide excellent coverage of South America, Africa, and Antarctica (see Figure 1). This is to say that there are many infrasound arrays in regions many thousands of kilometers from the closest seismic array.

The importance of the IMS seismic arrays for global event detection must not be underestimated. All of the phase readings from the Reviewed Event Bulletin (REB) of the International Data Center (IDC) are now sent to the International Seismological Center (ISC, http://www.isc.ac.uk) for inclusion in their bulletin. Figure 2 shows a subset of the events in the ISC bulletin from 2009 and 2010, together with the locations of the IMS seismic arrays operating in this time period. What the events displayed have in common is that they are all defined only using phases recorded on IMS seismic arrays. These events all have magnitude below 5 ; larger events would also have been detected and recorded on national networks. It is typical that regional and teleseismic phases from these events are registered on many arrays, each with a Signal-to-Noise Ratio (SNR) of, for example, 10 or less. It figures that, without the noise suppression resulting from the stack-and-delay beamforming over the arrays, the signals are likely to evade detection on the majority of 3-component stations. The locations of over 5000 events are shown in Figure 2, over and above what would have been detected by national networks alone, and it is clear that this is a significant proportion of the low-magnitude seismicity in the oceanic fault zones of the Asian Pacific. It is likely that a similar improvement in the characterization of seismicity would be observed for other remote regions and oceanic fault zones if a significant number of seismic arrays were to be deployed in suitable places.

The purpose of a seismic station is to detect phase arrivals, and to associate these detections with parameters which characterize the signals. Typical parameters of interest are the backazimuth, indicating the direction from which a signal came, and the apparent velocity, usually indicating which kind of phase has been detected (e.g. regional $P$, regional $S$, teleseismic $P$ etc.). This information, together with arrival-time data, allows detections from different stations to be associated to form event hypotheses. Detections are only likely to be associated with a given event hypothesis if the time, phase definition, and backazimuth are consistent with the origin time and location estimate. Parameters are estimated on 3-C stations using polarization analysis (e.g. Vidale, 1986) and on arrays using beamforming and related techniques (e.g. Schweitzer, 2014). Kennett (2002), chapter 23 in particular, provides an excellent overview of the processing and interpretation of regional seismic signals using both arrays and 3-C stations. The improvement in signal detectability on arrays through beamforming is significant, and parameter estimation using the time-delays between the signals on the neighboring sites of an array is almost always superior to that possible using only a 3-C station (Harris, 1990; Kværna and Ringdal, 1992). This is particularly the case as the SNR decreases (Harris, 1990) and for S-phases, for which the particle motion is far more complex than for P-phases. The superiority of the performance of the IMS array stations, compared with that of the IMS 3-C stations, is demonstrated unequivocally by Kværna and Ringdal (2013). The ability to exploit the subtle 
changes in the wavefield that occur between closely spaced seismometers has many applications beyond the detection and identification of signals. IMS array data has been used to locate and classify the sources of ocean-generated microseisms (e.g. Koper et al., 2003; Gal et al., 2014), for imaging of the deep earth (e.g. Koper et al., 2009), and for tracking earthquake ruptures (e.g. Guilbert et al., 2005).

It is worth taking a look at the global infrasound array network: not only at the geographic distribution of stations, but also at the array designs themselves. The arrays are optimized for detecting low frequency atmospheric sound signals propagating over the sensors at a few hundreds of meters per second. It may not be obvious that the designs are also well suited to the detection and characterization of seismic signals propagating at apparent velocities an order of magnitude greater. It is in fact already the case that seismic arrivals, converted to pulses of air pressure at the microbarograph sensors, are already recorded on the IMS infrasound arrays and used to locate seismic events in the Reviewed Event Bulletin (REB). The first phase arrival in the REB from the 2013 North Korean nuclear test is a seismic Pn phase, converted into an acoustic signal on the I45RU infrasound array in the Russian Federation. Figure 3 displays the initial P-arrival from the Magnitude 7.6 Kashmir earthquake in 2005 recorded on the I31KZ infrasound array in Kazakhstan, a phase that was also used in the REB. It is clear from the slowness grid in the right hand panel of Figure 3 that the geometry of this infrasound array provides an impressive resolution capability for estimating the backazimuth and apparent velocity of the phase (which is identified correctly on the basis of this parameter measurement). It is clear from the waveforms that the SNR of the seismic arrival on the microbarograph is significantly poorer than that on the almost co-located seismometer, and this is why only the very strongest of seismic signals are detected and analyzed on the infrasound arrays.

The true performance and capability of seismometer arrays is unknown until the instruments are deployed and recording data. However, we aim to demonstrate from a purely geometrical perspective that the infrastructure in place at many of these infrasound arrays would support arrays of seismic sensors with excellent potential for the detection and classification of seismic signals. We will argue that co-located seismic and acoustic arrays would not only enhance greatly the seismic monitoring capability globally, and in the Southern Hemisphere in particular, it would also provide significant added value for the existing infrasound arrays. 


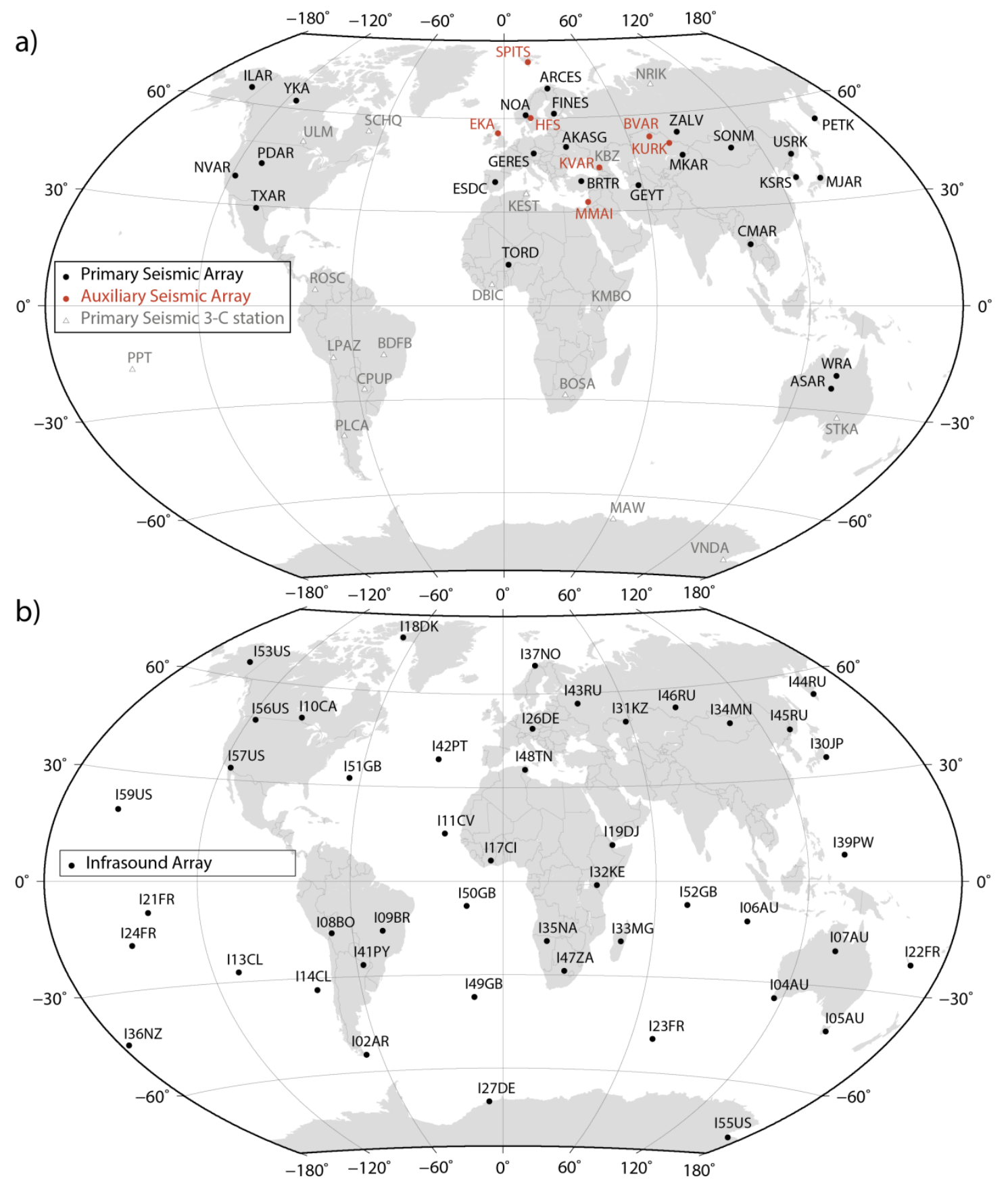

Figure 1 The status of the IMS global seismic (a) and infrasound (b) networks as of August 2014. Auxiliary 3-C stations are not shown. 


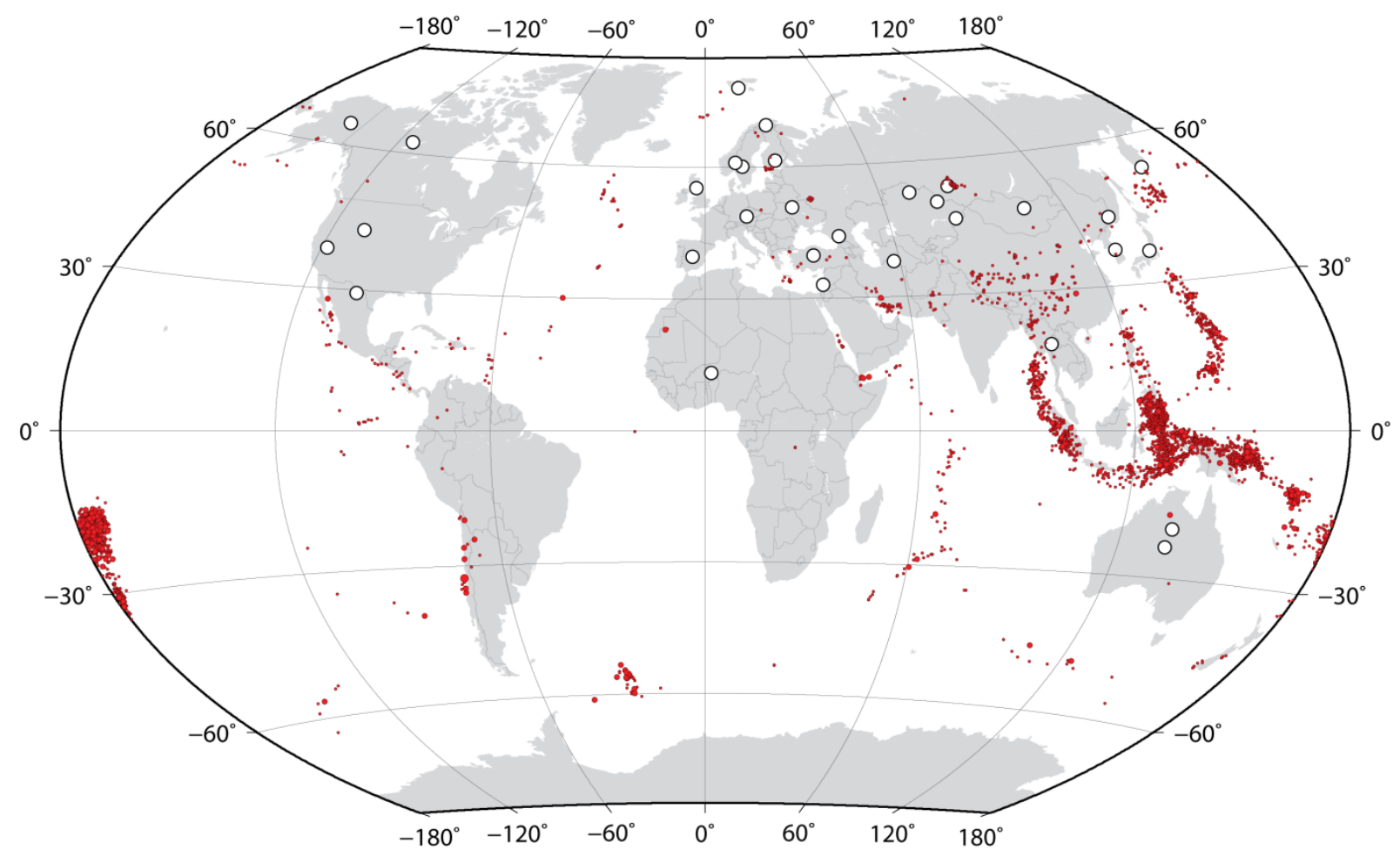

Figure 2 Seismic events (red) in the International Seismological Center (ISC) event bulletin in 2009 and $\mathbf{2 0 1 0}$ which are constrained only using phase readings from IMS seismic array stations (white circles).

a)

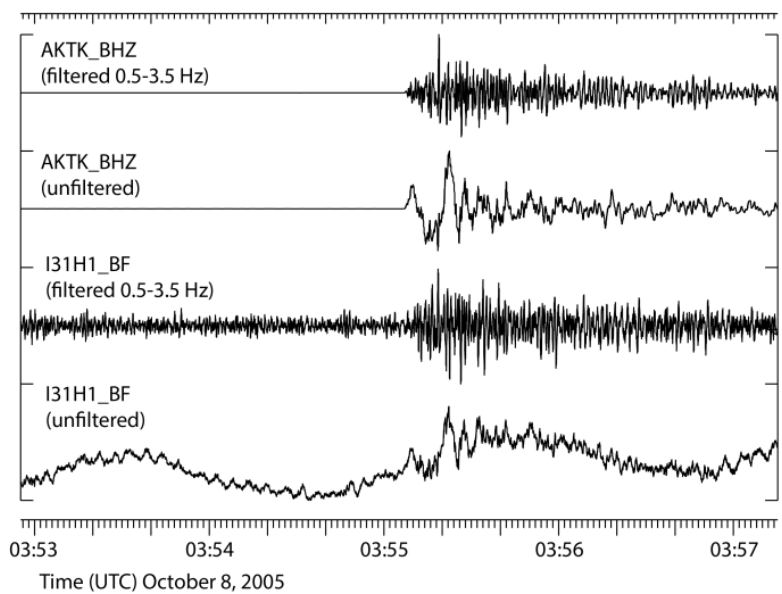

b)

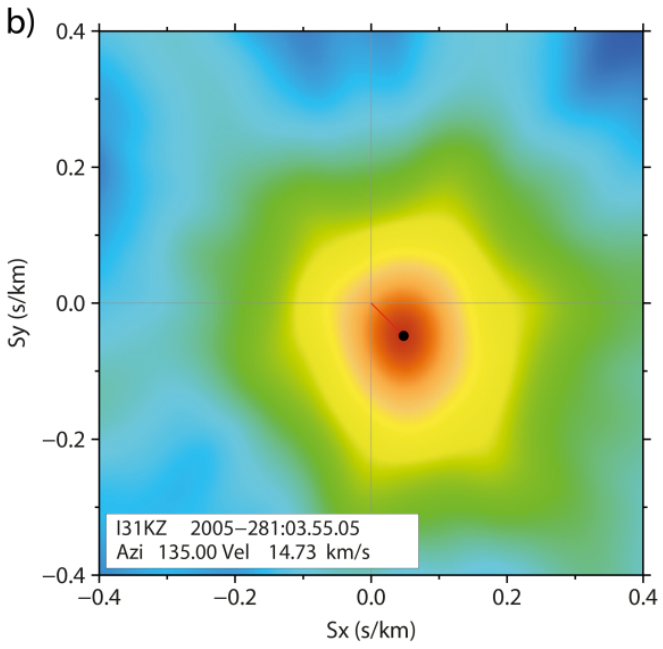

Figure 3 (a) Signal from the October 8, 2005, magnitude 7.6 Kashmir earthquake recorded on the I31KZ infrasound array in Kazakhstan (distance 19.5 degrees) and the AKTK seismic station $3 \mathbf{~ k m}$ from the displayed microbarograph. (b) Direction estimate from all microbarograph channels of $131 \mathrm{KZ}$ for this P-wave arrival in frequency band 1-4 $\mathrm{Hz}$ using correlation procedure of Brown et al. (2002). 


\section{THE GLOBAL NETWORK OF INFRASOUND ARRAYS}

The IMS infrasound arrays have been deployed worldwide over the last 15 years or so (Christie and Campus, 2010). Table 1 gives the locations of the 46 arrays certified and sending data as of August 2014. An additional 13 arrays are either planned or under construction, based on coordinates specified in the treaty text (http://www.ctbto.org/the-treaty/treaty-text/). A key parameter to the effectiveness of a sensor array for monitoring a particular kind of signal is the array geometry. Gibbons (2014) considers the geometries of the IMS seismic arrays, with well over an order of magnitude difference between the aperture of the largest array and the aperture of the smallest array. This has enormous consequences for the kind of signal that the arrays are optimal for processing. The largest seismic arrays (aperture $>20 \mathrm{~km}$ ) are legacy arrays optimized for detecting and measuring lower frequency teleseismic signals, and struggle with high frequency regional phases due to aliasing and incoherence of signals between sensors. The smallest aperture arrays (aperture < 3-4 km) were optimized for processing high frequency regional phases and provide far more limited beamforming gain and slowness resolution for teleseismic signals. Between the extremes, a number of so-called hybrid arrays exist which provide a compromise. The range of geometries of the seismic arrays stems from the fact that they were designed for different monitoring objectives. The infrasound arrays were designed to comprise a unified network and so are far more similar in geometry (Figure 4).

The arrays in Figure 4 are color-coded to indicate, on the basis of their geographical location alone, how a seismic array in this location is likely to add to the global seismic monitoring capability. Red stations are infrasound arrays that are on continents with either no existing seismic arrays or only a single seismic array. Orange stations are on continents with several seismic arrays, even though there may be a significant distance between them and the closest seismic array. The yellow stations are only hundreds of kilometers from the closest seismic array and so may provide great information on regional seismicity, without having a great impact on global monitoring. The green stations have seismic arrays within a few $\mathrm{km}$ and, other than providing sensor redundancy, would likely have little impact. (A small aperture array close to a larger, sparser, array may of course better resolve high frequency phases.) Special colors have been given for stations in the Arctic and Antarctic, and for stations on oceanic islands. Polar stations could provide useful information on ice-related as well as regional seismicity; there is already a small-aperture research array in Antarctica (Büßelberg et al., 2001). The island stations are likely to be subject to far higher seismic background noise and less likely to detect and classify signals than continental stations at comparable distances. Then again, many may be closer to the regions of under-characterized seismicity and an array would lower the detection threshold and enhance the estimation capability relative to a 3-C station in the same location. 
Table 1: Locations and dimensions of IMS infrasound arrays as of August 2014. The aperture is defined as the greatest inter-site distance on the array.

\begin{tabular}{|c|c|c|c|c|c|c|c|}
\hline $\begin{array}{l}\text { Station } \\
\text { code }\end{array}$ & $\begin{array}{r}\text { Starting } \\
\text { date }\end{array}$ & Latitude & Longitude & $\begin{array}{r}\text { Elev. } \\
(/ \mathrm{km})\end{array}$ & NS & $\begin{array}{l}\text { Aper } \\
(/ \mathrm{m})\end{array}$ & Station name and location \\
\hline I02AR & $2006-124$ & -54.5806 & -67.3092 & 0.0940 & 5 & 1437 & Ushuaia, Argentina \\
\hline I04AU & 2006-032 & -34.5976 & 116.3567 & 0.1671 & 8 & 2419 & Shannon, Australia \\
\hline I05AU & 2003-088 & -42.4908 & 147.6806 & 0.3500 & 8 & 2235 & Hobart, Tasmania, Australia \\
\hline I06AU & 2011-304 & -12.1464 & 96.8203 & -0.0168 & 8 & 1555 & Cocos Islands, Australia \\
\hline IO7AU & $2000-133$ & -19.9348 & 134.3295 & 0.3855 & 8 & 2260 & Warramunga, Australia \\
\hline 108BO & $2000-003$ & -16.2152 & -68.4535 & 4.0957 & 4 & 2289 & Penas-Bolivia, Bolivia \\
\hline I09BR & $2001-171$ & -15.6380 & -48.0164 & 1.1853 & 4 & 2264 & Brasilia, Brazil \\
\hline I10CA & $1999-124$ & 50.2015 & -96.0269 & 0.2466 & 4 & 2606 & Lac du Bonnet, Canada \\
\hline I11CV & $2007-150$ & 15.2573 & -23.1839 & 0.0443 & 8 & 1965 & Cape Verde \\
\hline I13CL & $2005-076$ & -27.1273 & -109.3627 & 0.1635 & 8 & 2805 & Easter Island, Chile \\
\hline $\mathrm{I} 14 \mathrm{CL}$ & 2004-115 & -33.6538 & -78.7960 & 0.3879 & 8 & 2647 & Robinson Crusoe Island, Chile \\
\hline $\mathrm{I} 17 \mathrm{Cl}$ & $2002-088$ & 6.6704 & -4.8569 & 0.1563 & 4 & 2943 & Dimbokro, Ivory Coast \\
\hline I18DK & $2002-248$ & 77.4756 & -69.2878 & 0.0875 & 8 & 1172 & Qaanaaq, Greenland (Denmark) \\
\hline I19DJ & $2011-213$ & 11.4740 & 43.1731 & 0.0212 & 8 & 2002 & Djibouti \\
\hline I21FR & $2005-088$ & -8.8678 & -140.1591 & 0.8060 & 4 & 1831 & Marquesas Island, France \\
\hline I22FR & $2002-088$ & -22.1844 & 166.8459 & 0.2716 & 4 & 2137 & Portlaguerre, France \\
\hline I23FR & $2007-344$ & -49.3458 & 70.2416 & 0.0842 & 15 & 1597 & Kerguelen, France \\
\hline I24FR & $2000-071$ & -17.7493 & -149.2958 & 0.1168 & 5 & 3895 & Tahiti, France \\
\hline I26DE & $1999-305$ & 48.8516 & 13.7131 & 1.1109 & 5 & 2563 & Freyung, Germany \\
\hline I27DE & 2003-046 & -70.7011 & -8.3029 & -0.0570 & 9 & 1928 & Neumayer, Antarctica (DE) \\
\hline I30JP & 2005-059 & 35.3078 & 140.3138 & 0.0524 & 6 & 2129 & Isumi (Japan) \\
\hline I31KZ & $2006-131$ & 50.4070 & 58.0348 & 0.3694 & 8 & 2194 & Aktjubinsk (Kazakhstan) \\
\hline I32KE & $2003-168$ & -1.2422 & 36.8272 & 1.6616 & 7 & 1129 & Nairobi (Kenya) \\
\hline I33MG & $2001-288$ & -19.0109 & 47.3050 & 1.3849 & 4 & 2475 & Anaananarivo, Madagascar \\
\hline I34MN & 2008-014 & 47.8017 & 106.4101 & 1.2452 & 8 & 2974 & Songino, Mongolia \\
\hline I35NA & 2003-078 & -19.1913 & 17.5768 & 1.2525 & 7 & 2046 & Tsumeb, Namibia \\
\hline I36NZ & $2004-314$ & -43.9166 & -176.4834 & 0.0137 & 8 & 2863 & Chatham, New Zealand \\
\hline I37NO & $2013-100$ & 69.0758 & 18.6076 & 0.0779 & 10 & 1962 & Bardufoss, Norway \\
\hline I39PW & $2005-222$ & 7.5355 & 134.5470 & 0.1000 & 7 & 2440 & Palau \\
\hline I41PY & 2003-078 & -26.3423 & -57.3119 & 0.1637 & 4 & 2286 & Villa Florida, Paraguay \\
\hline I42PT & $2010-313$ & 39.0423 & -28.0055 & 0.2844 & 8 & 1920 & Azores, Portugal \\
\hline I43RU & $2009-140$ & 56.7214 & 37.2176 & 0.1200 & 6 & 1558 & Dubna, Russia \\
\hline I44RU & $2006-303$ & 53.1058 & 157.7139 & 0.3800 & 4 & 1906 & Petropavlovsk-Kamchatsky, RU \\
\hline I45RU & $2008-315$ & 44.1999 & 131.9773 & 0.1500 & 4 & 2171 & Ussuriysk, Russia \\
\hline I46RU & $2006-334$ & 53.9487 & 84.8189 & 0.2320 & 4 & 2849 & Zalesovo, Russia \\
\hline I47ZA & $2005-312$ & -28.6211 & 25.2352 & 1.3057 & 8 & 1696 & Boshof, South Africa \\
\hline I48TN & $2006-153$ & 35.8052 & 9.3230 & 0.8482 & 7 & 1841 & Kesra, Tunisia \\
\hline I49GB & $2005-083$ & -37.0900 & -12.3319 & 0.0806 & 5 & 2149 & Tristan da Cuhna, UK \\
\hline I50GB & 2005-104 & -7.9377 & -14.3752 & 0.1886 & 8 & 2776 & Ascension Island, UK \\
\hline I51GB & $2008-315$ & 32.3615 & -64.6987 & -0.0346 & 4 & 2396 & Bermuda, United Kingdom \\
\hline I52GB & $2002-352$ & -7.3778 & 72.4842 & 1.0000 & 7 & 1886 & Diego Garcia, United Kingdom \\
\hline I53US & $2002-260$ & 64.8750 & -147.8611 & 0.2003 & 8 & 1987 & Fairbanks, Alaska (USA) \\
\hline I55US & 2001-336 & -77.7315 & 167.5874 & 0.0418 & 9 & 1917 & Windless Bight, Antarctica (USA) \\
\hline I56US & $2002-276$ & 48.2641 & -117.1257 & 0.7628 & 9 & 2240 & Newport (USA) \\
\hline I57US & $2004-051$ & 33.6059 & -116.4533 & 1.2506 & 8 & 1454 & Pinõn Flat (USA) \\
\hline I59US & $2001-051$ & 19.5915 & -155.8936 & 1.0760 & 8 & 1888 & Hawaii (USA) \\
\hline
\end{tabular}




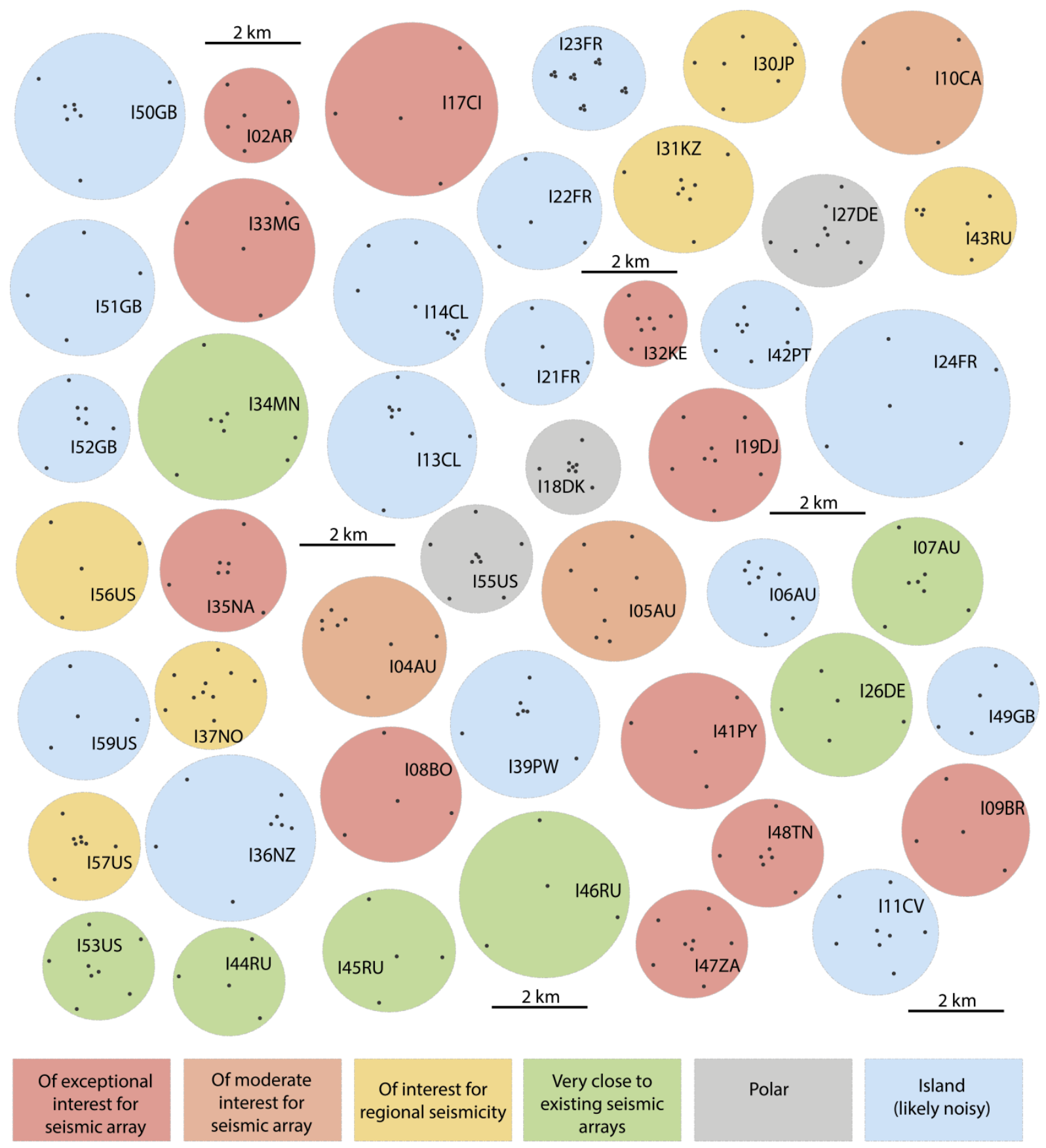

Figure 4 Configurations of all IMS infrasound arrays sending data as of August 2014. Color-coded as indicated for how useful a seismic array in that location would be for incremental capability to the monitoring of global seismicity.

A number of infrasound arrays are almost co-located with IMS 3-component seismic stations. $I 17 \mathrm{CI}$ is almost co-located with DBIC, I57US with PFO, I56US with NEW, I09BR with BDFB, I35NA with TSUM, I47NA with BOSA, 141PY with CPUP, I13CL with RPN, I31KZ with AKTO, 148TN with KEST and I10CA with ULM. These arrays are interesting to look at in particular since the data from the existing 3-C seismic station provides us with confidence that the sites of the infrasound sensors are also plausible candidate sites for seismic sensors. The microbarograph signal from the magnitude 7.6 earthquake in Figure 3 has a sufficient SNR in a very limited frequency band. Many hundreds of the significantly 
smaller aftershocks were very well recorded, typically at higher frequencies, on the AKTK station while not managing to generate a usable signal on the I31KZ microbarographs. We can estimate the performance of "an ideal seismic array" (i.e. one which does not suffer because of waveform dissimilarity between sensors) by duplicating the signal from the 3-C station at each site of the infrasound array and delaying by the appropriate time-offsets. Figure 5 shows this array response for the Kashmir signal in the $2-5 \mathrm{~Hz}$ frequency band, indicating a slowness estimate that identifies the backazimuth and apparent velocity with adequate resolution. The true frequency-wavenumber ( $\mathrm{f}-\mathrm{k}$ ) spectrum for a given signal and a given frequency band can only be determined experimentally since the deviation from the plane-wave model resulting from scattering and diffraction will vary from location to location. It is also assumed that the ground coupling at each of the infrasound sensor sites is as good as at the seismometer site. In practice, seismometers are placed if possible on bedrock for maximal coupling to the solid earth whereas microbarographs are often placed on soft sediments or in soil. It may therefore be necessary to make borehole installations at some of these sites in order to provide seismic data of sufficient quality.

a)

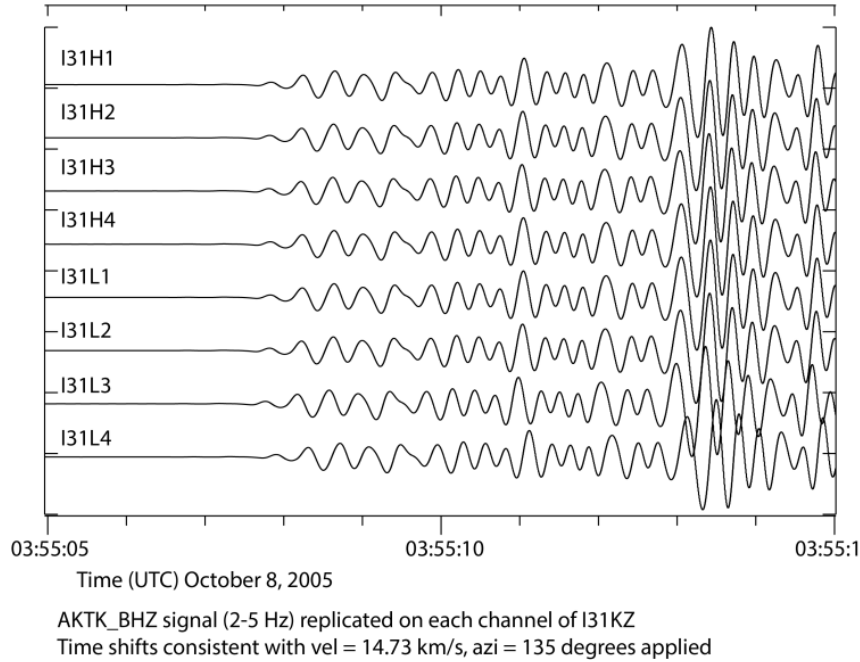

b)

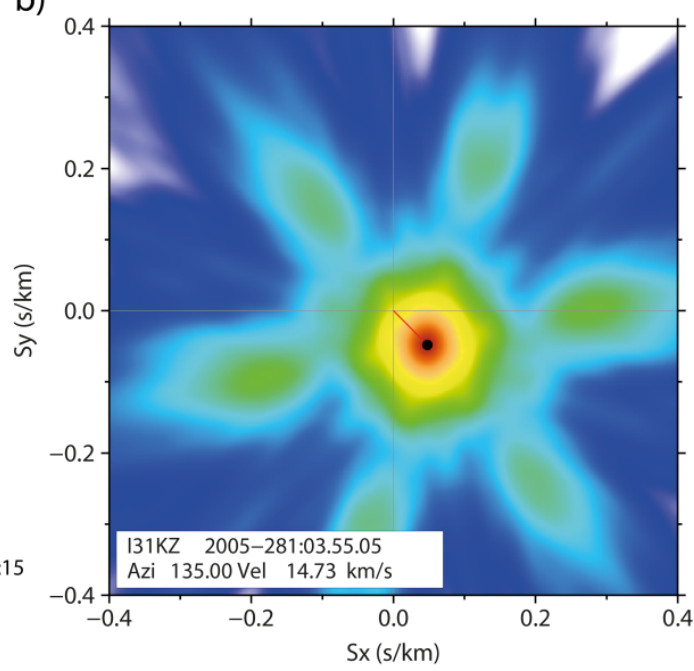

Figure 5 Simulation of the array response of I31KZ to the Kashmir P-wave signal in the 2-5 $\mathrm{Hz}$ band (b), estimated by assuming each sensor of I31KZ to contain the signal from the AKTK_BHZ channel with an appropriate time delay (a). 


\section{AN EXPLORATION OF ARRAY RESPONSE FUNCTIONS}

The performance of an array is defined by the array response function which, for a given frequency range, indicates the slowness resolution and can indicate where estimates could be compromised due to sidelobes. Our main concern is to be able to measure the backazimuth and apparent velocity with a sufficient accuracy such that a phase association/event location routine can use the arrival to define and constrain an event. In particular, we should be able to differentiate between regional $P$, regional $\mathrm{S}$ and teleseismic $\mathrm{P}$ phases. Figure 6 displays a regional signal recorded at the 3-C IMS station TSUM together with the "empirical array response functions" for the $\mathrm{Pn}$ and $\mathrm{Sn}$ phases at the almost co-located I35NA infrasound array. Here, we have bandpass filtered in a suitable frequency band (2-5 $\mathrm{Hz}$ ), taken a small segment of this signal ( 3.5 seconds long), and delayed across the different sensors to simulate the predicted speed and direction of the incoming signal. We follow the principle described by Gibbons et al. (2011), that parameter measurement of S-phases is likely to be more reliable on the rotated horizontal components than on the vertical components. The classification is unambiguous for these regional phases. This frequency band, with an optimal compromise between SNR and anticipated high inter-site coherence, results in significant and non-overlapping peaks in the $\mathrm{f}-\mathrm{k}$ spectra. The slowness estimates are obtained using the broadband procedure of Kværna and Doornbos (1986); the modestly broader slowness response for the S-phase is likely to reflect a slightly lower dominant frequency for this phase.

In Figure 7, we display the more traditional view of the array response function - centered on the zero slowness vector for generic phases - for 6 representative arrays. This figure demonstrates that the different array geometries do have a significant effect on the anticipated quality of slowness estimates. 137NO, with 10 sensors arranged in an approximate log-period radius concentric circle model (see, e.g. Harjes, 1990), has superb sidelobe suppression. I08BR, with only 4 sparse sensors over a $2 \mathrm{~km}$ radius has significant sidelobes. While there are no hard and fast rules as to which geometrical layout makes a good seismic array, a high degree of azimuthal symmetry, a large number of sensors, and as high a range of inter-site spacings as possible generally contribute to a robust array response function. We would stress that a sparse array configuration should not discourage experimentation in the setting up of a seismic array co-located with the infrasound sensors. An experimental deployment which demonstrates high quality seismic signals but with aliasing problems could be equipped with strategically positioned additional sensors designed to suppress sidelobes in the array response function. 
a)

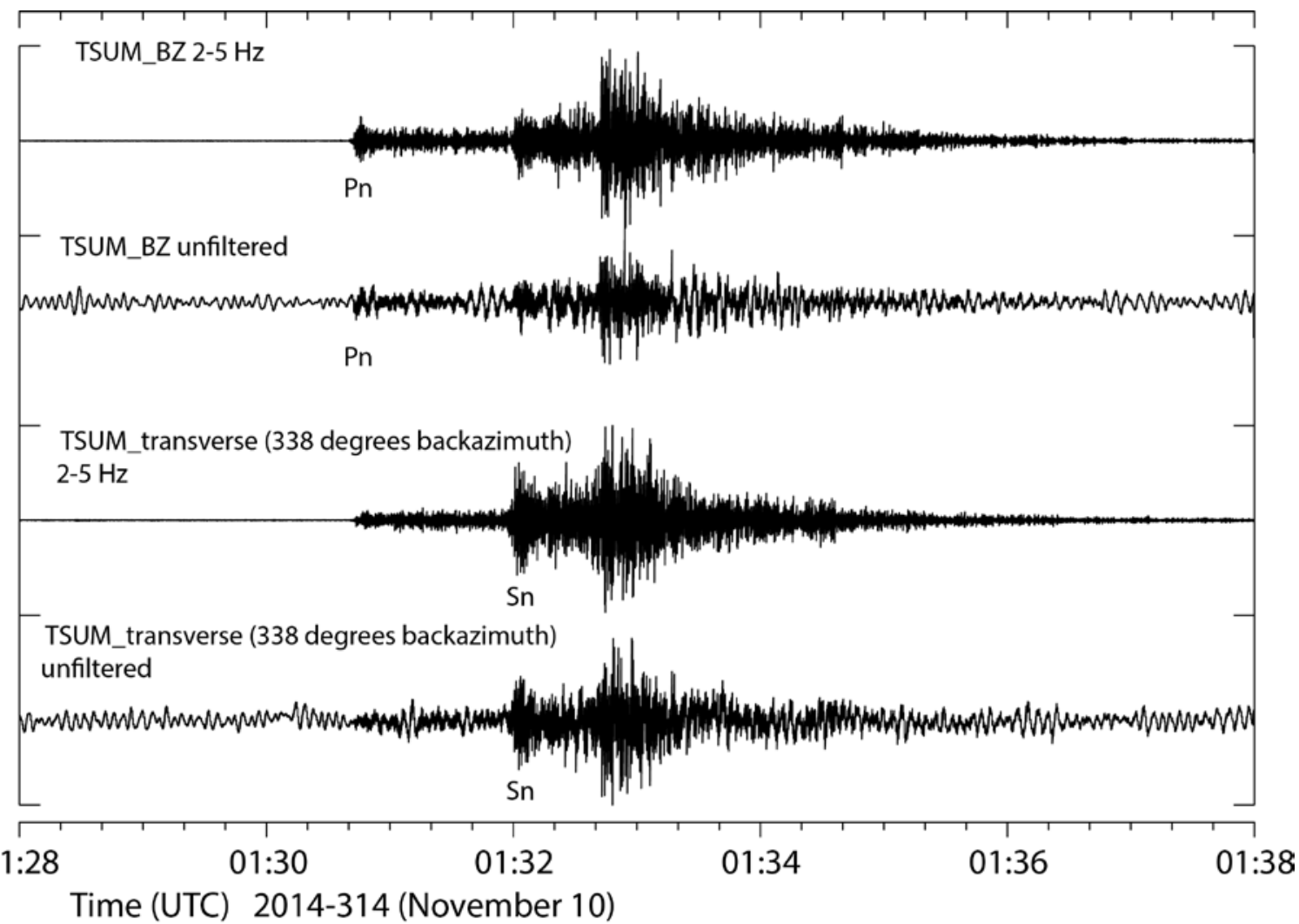

b)

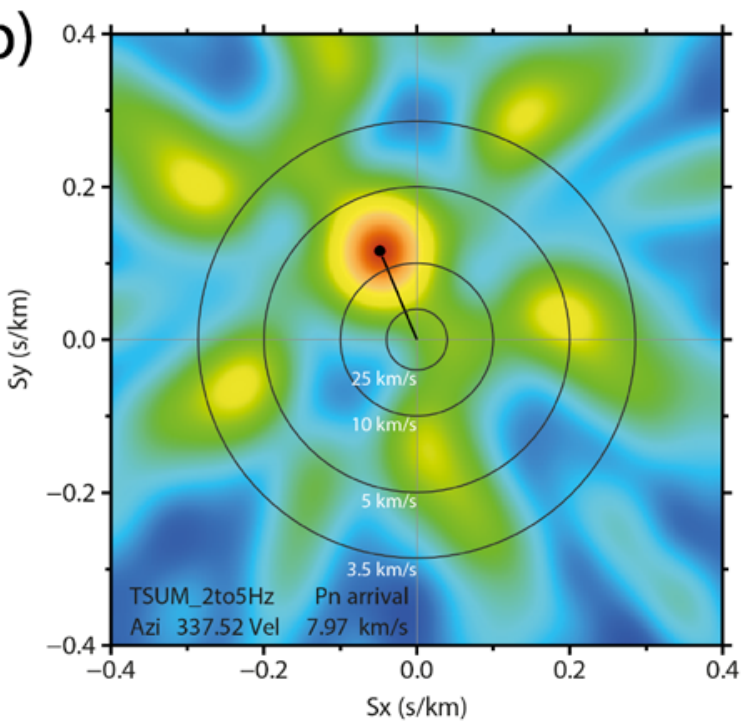

c)

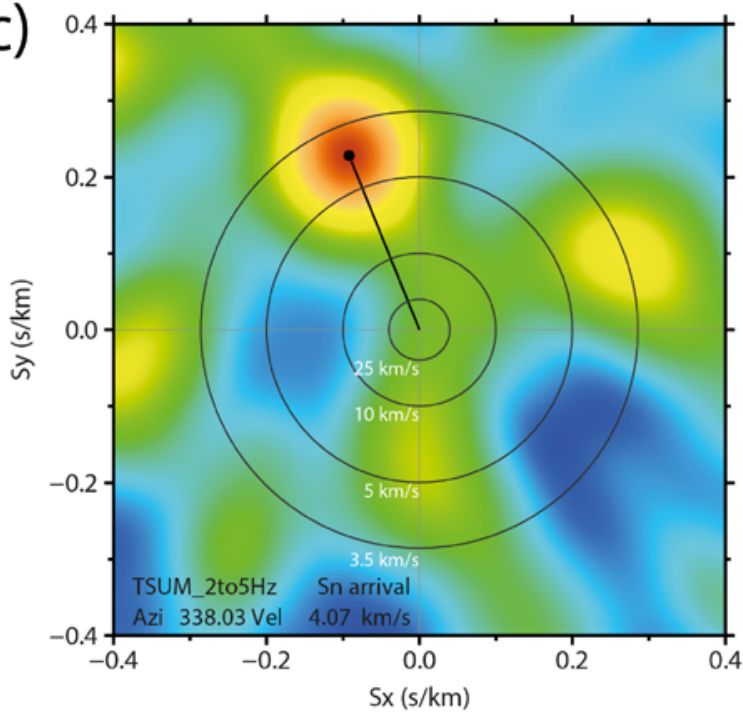

Figure 6 Waveforms on the IMS 3-C station TSUM (a) from an event at a distance of approximately 7 degrees together with the simulated responses of the almost co-located I35NA infrasound array for the Pn (b) and Sn (c) arrivals. It is assumed that each site houses a broadband 3-C seismometer displaying a signal identical to that on the vertical and transverse components respectively of TSUM, simply delayed by the theoretical time-shifts. 
a)

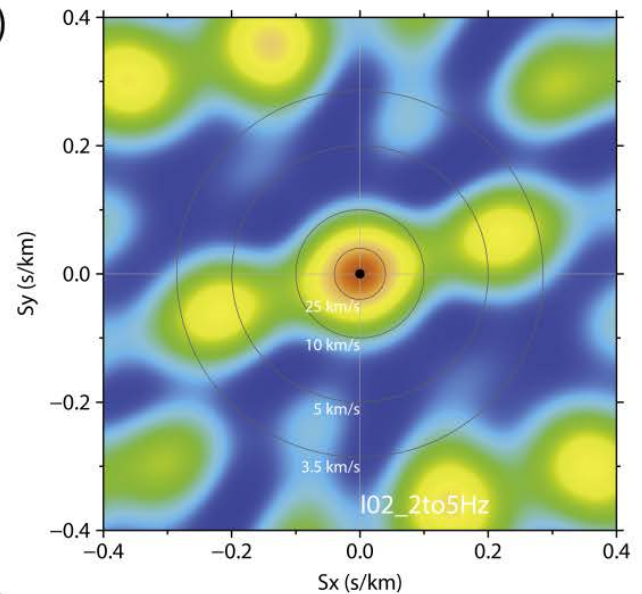

c)

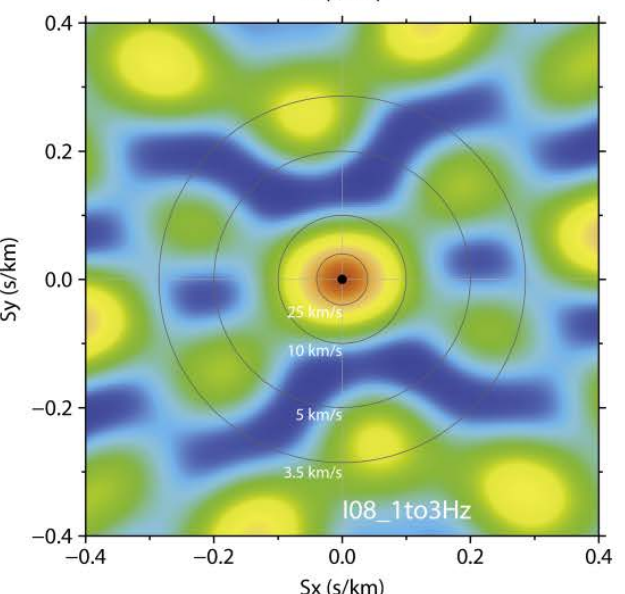

e)

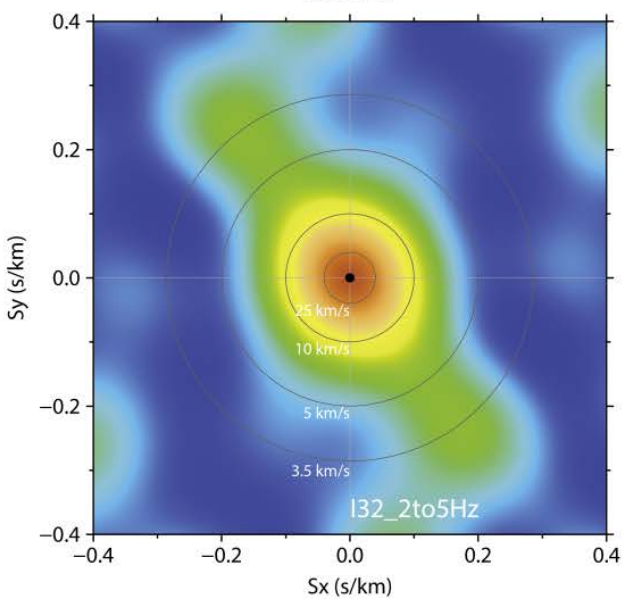

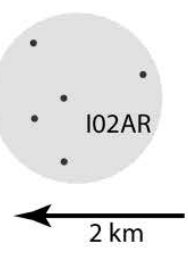

b)
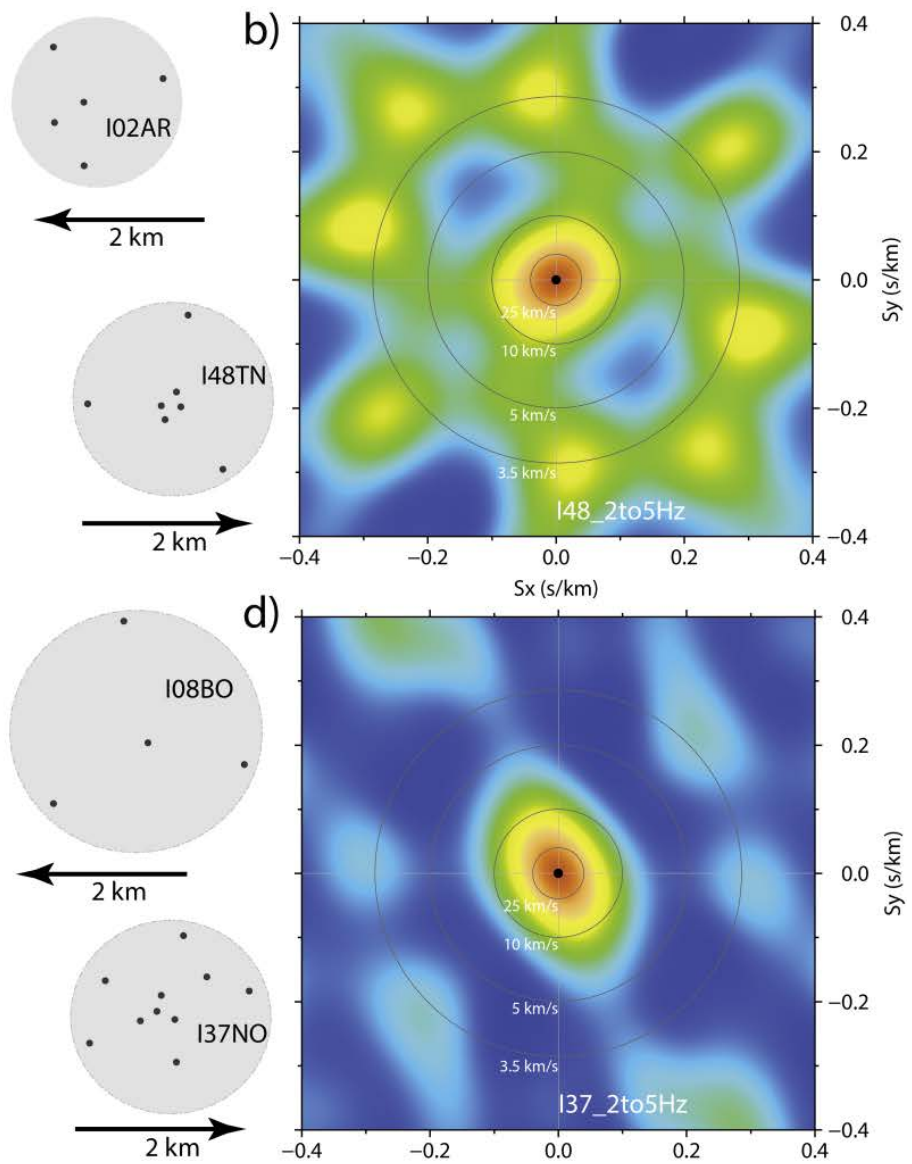

d)
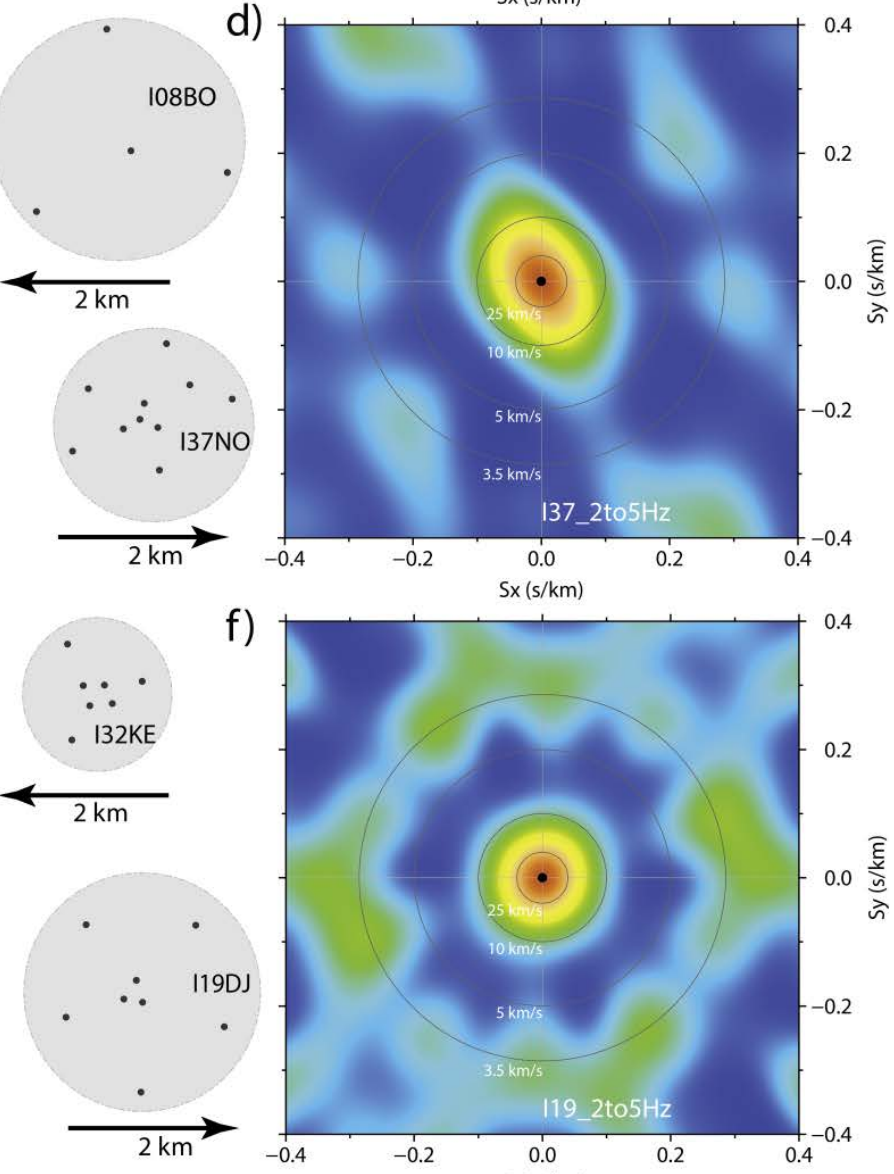

f)

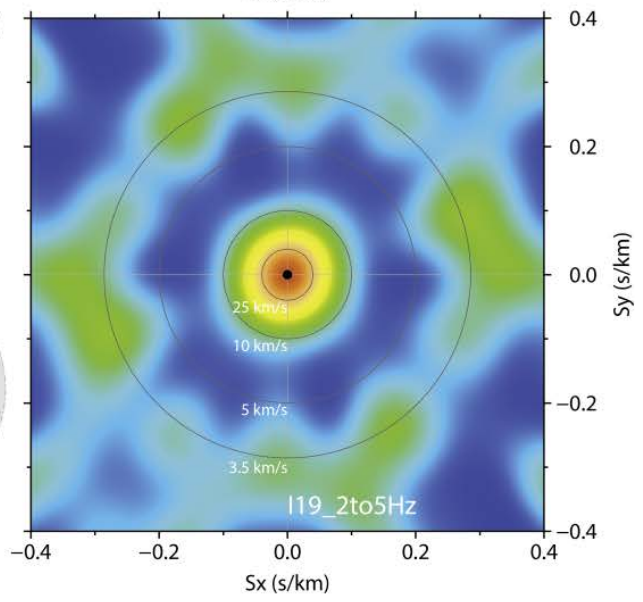

Figure 7 Theoretical array response functions for the infrasound arrays I02AR (a), 148TN (b), 108BO (c), I37NO (d), I32KE (e), and I19DJ (f). All panels are for the 2-5 Hz band except (c) for which the 1-3 $\mathrm{Hz}$ band is displayed. Comparing panels $(c)$ and (d) in particular, we see how the sidelobes are reduced by the presence of additional more closely spaced sensors.

\section{CONCLUSIONS}

Seismic arrays with apertures of a few kilometers provide a significantly enhanced ability to detect and characterize seismic phase arrivals, almost always outperforming co-located single 3-component stations. It can be demonstrated that significant numbers of additional seismic events in remote 
regions, not accessible to local monitoring, are detected by distant array stations only. For historical reasons, the seismic arrays of the IMS are almost all in the Northern Hemisphere with vast continental regions in the Southern Hemisphere many thousands of kilometers from the closest seismic array. The global IMS network of infrasound arrays on the other hand has a remarkably homogeneous global coverage with many arrays in South America and Africa in particular. We have reviewed the geographical distribution and spatial designs of the IMS infrasound arrays and argue, from a purely geometrical point of view, that many of the arrays would constitute small-aperture seismic arrays that would make a considerable contribution to enhanced seismic monitoring globally. The improvement is likely to be greatest for seismicity within regional distances of the stations, although the deployment of arrays in Africa and South America in particular may enhance greatly the image of seismicity along oceanic plate boundaries in the Indian, South Atlantic, Pacific, and Southern Oceans. An improvement in the detection threshold and location capability for subduction-zone events in South America could enhance significantly our picture of potentially hazardous seismicity in that part of the world.

The quality of seismic signals recorded at the exact locations of the infrasound sensors can only be determined experimentally although, in many cases, there are single-site 3-component stations very close by that have over many years recorded high quality seismic data. These stations give reason to believe that many of the infrasound arrays are in regions where the deployment of seismic arrays would have significant merit. Many regional events recorded on these 3-C stations may fail to be characterized and located due to the inability to estimate parameters robustly using 3-C analysis. This is particularly likely to be the case for automatic processing. When deploying a new seismic array, experimental analysis of signal and noise coherence is crucial (e.g. Braun and Schweitzer, 2008). The infrasound arrays may provide an existing infrastructure that supports the experimental deployment of seismic arrays, such that the costs of deployment do not necessarily need to include power supply or data transmission. A deployment could take place in stages, starting with seismic sensors simply placed in the pits containing the microbarographs. If, for example, the infrasound sensors are in soft sediments or soil with poor seismic coupling, borehole deployments may be necessary to ensure seismic data of sufficiently high quality. Exact co-location of seismic and infrasound sensors need not be necessary for the sensors to be able to exploit a common infrastructure; a slightly different configuration for the seismic sensors may improve significantly the array response function.

There is obvious benefit for countries in an enhanced ability to detect and locate natural or induced seismicity on their territory that exceeds that provided by existing seismic networks. The co-location of seismic and infrasonic sensors in arrays (e.g. Stump et al., 2004) has enormous benefits for analyzing and characterizing infrasound signals. An IMS infrasound array may detect many signals from seismo-acoustic events at regional distances that are not exploited at the IDC since they may not be associated with signals recorded at other stations. A co-located seismic array may give the host nation the immediate ability to identify a known source of an acoustic signal (for example an open-cast mine). Equally importantly, the absence of a seismic signal for a given acoustic signal may alert the operators to an event that may warrant extra examination: possibly an airborne source.

We believe that these empirical array response functions provide sufficient motivation for experimental deployments to assess the potential for co-locating seismic and infrasonic sensors in the IMS infrasound arrays. The estimates do not take into account the loss of coherence between sensors that occurs as the signal frequency increases, since this can only be determined by deploying 
instruments and recording data. However, empirical evidence with existing seismic arrays of comparable dimensions indicate that this is not usually an issue for signals between 1 and $5 \mathrm{~Hz}$. Even for cases where signal coherence is a significant problem, we can often exploit multi-channel processing to great effect for unconventional signal processing. Gibbons and Ringdal (2012) demonstrate very robust monitoring of a nuclear test site using highly incoherent regional signals on the MJAR array in Japan; multi-channel correlation detectors do not require inter-site signal coherence. Similarly, Harris and Kværna (2010) demonstrate that aberrations from the plane-wave signal model can be accounted for empirically in matched field processing. Our primary aim has been to demonstrate that there are benefits of deploying small aperture seismic arrays globally, and that the IMS infrasound arrays may provide an infrastructure that allows this to happen - providing benefit to the host nations both in terms of enhanced seismic monitoring of their own territory and improved exploitation of the infrasound data collected.

\section{DATA AND RESOURCES}

The bulletin of the International Seismological Center, including all readings from the IMS stations, is available from http://www.isc.ac.uk (last accessed May 2015) and the text of the Comprehensive Nuclear-Test-Ban Treaty is available from http://www.ctbto.org/the-treaty/treaty-text/ (last accessed May 2015).

Data from the AKTK station is courtesy of the Kazakhstan National Data Center and was obtained via the Integrated Research Institutions for Seismology (IRIS) Data Management Center (DMC) from the KZ network at http://ds.iris.edu/ds/ (last accessed May 2015). Data from the TSUM station is available from the IRIS DMC from the network IU.

All other data was obtained via the International Data Center (IDC) for the Comprehensive NuclearTest-Ban Treaty Organization (СТВTO). Infrasound data from the following stations is available from the IRIS DMC under the network code IM: I04AU, I06AU, I07AU, I49GB, I51GB, 152GB, I53US, I55US, I56US, I57US, I58US, 159US. Data from I37NO is available from NORSAR at http://www.norsardata.no/NDC/data/autodrm.html (last accessed May 2015).

\section{ACKNOWLEDGEMENTS}

All maps generated by the GMT package, Wessel and Smith (1995).

\section{REFERENCES}

Ammon, C. J., T. Lay, and D. W. Simpson (2010), Great Earthquakes and Global Seismic Networks, Seismological Research Letters, 81, 965-971, doi:10.1785/gssrl.81.6.965 
Braun, T. and J. Schweitzer (2008), Spatial Noise-Field Characteristics of a Three-Component Small Aperture Test Array in Central Italy, Bulletin of the Seismological Society of America 98, 18761886, doi:10.1785/0120070077

Brown, D. J., C. N. Katz, R. Le Bras, M. P. Flanagan, J. Wang, and A. K. Gault (2002). Infrasonic Signal Detection and Source Location at the Prototype International Data Centre, Pure and Applied Geophysics, 159, 1081-1125, doi:10.1007/s00024-002-8674-2

Büßelberg, T., C. Müller, and A. Eckstaller (2001), The Neumayer Array and Its Impact on Seismological Research in the South Atlantic and Antarctica, Terra Antartica 8, 41-48

Christie, D. R., and P. Campus (2010). The IMS Infrasound Network: Design and Establishment of Infrasound Stations, Chapter 2 in "Infrasound Monitoring for Atmospheric Studies", Le Pichon, A., Blanc, E., and Hauchecorne, A. (eds.), Springer Science and Business Media, B. V, 29-75. doi:10.1007/978-1-4020-9508-5 2

Clinton, J. F., M. Nettles, F. Walter, K. Anderson, T. Dahl-Jensen, D. Giardini, A. Govoni, W. Hanka, S. Lasocki, W. S. Lee, David McCormack, S. Mykkeltveit, E. Stutzmann, and S. Tsuboi (2014), Seismic Network in Greenland Monitors Earth and Ice System, EOS Transactions, AGU, 95, 1314, doi:10.1002/2014eo020001

Dahlman, O., S. Mykkeltveit, H. Haak (2009), Nuclear Test Ban: Converting Political Visions to Reality, Springer Science+Business Media B.V, Dordrecht, The Netherlands ISBN: 978-1-4020-6883-6 (Print) 978-1-4020-6885-0 (Online) 10.1007/978-1-4020-6885-0

Dahlman, O., J. Mackby, S. Mykkeltveit, H. Haak (2011), Detect and Deter: Can Countries Verify the Nuclear Test Ban? Springer Science+Business Media B.V, Dordrecht, The Netherlands. ISBN: 978-94-007-1675-9 (Print) 978-94-007-1676-6 (Online) doi:10.1007/978-94-007-1676-6

Douglas, A. (2002), Seismometer Arrays - Their Use in Earthquake and Test Ban Seismology, in "International Handbook of Earthquake and Engineering Seismology", ed.s Lee, W. H. K., Kanamori, H., Jennings, P. C., and Kisslinger, C., Academic Press, 357-367. doi:10.1016/s0074$\underline{6142(02) 80226-1}$

Gal, M., Reading, A. M., Ellingsen, S. P., Koper, K. D., Gibbons, S. J., and Näsholm, S. P. (2014), Improved implementation of the $\mathrm{fk}$ and Capon methods for array analysis of seismic noise, Geophysical Journal International 198, 1045-1054, doi:10.1093/gii/ggu183

Gibbons, S. J. (2014), The Applicability of Incoherent Array Processing to IMS Seismic Arrays, Pure and Applied Geophysics 171, 377-394, doi:10.1007/s00024-012-0613-2

Gibbons, S. J., J. Schweitzer, F. Ringdal, T. Kværna, S. Mykkeltveit and B. Paulsen (2011), Improvements to Seismic Monitoring of the European Arctic Using Three-Component Array Processing at SPITS, Bulletin of the Seismological Society of America 101, 2737-2754, doi:10.1785/0120110109

Gibbons, S. J. and F. Ringdal (2012), Seismic Monitoring of the North Korea Nuclear Test Site Using a Multichannel Correlation Detector, IEEE Transactions of Geoscience and Remote Sensing 50, 1897-1909, doi:10.1109/tgrs.2011.2170429 
Guilbert, J., Vergoz, J., Schisselé, E., Roueff, A., and Cansi, Y. (2005), Use of hydroacoustic and seismic arrays to observe rupture propagation and source extent of the $\mathrm{Mw}=9.0$ Sumatra earthquake, Geophysical Research Letters 32, L15310, doi:10.1029/2005gl022966

Harjes, H.-P. (1990), Design and siting of a new regional array in Central Europe, Bulletin of the Seismological Society of America 80, 1801-1817

Harris, D. B. (1990), Comparison of the direction estimation performance of high-frequency seismic arrays and three-component stations, Bulletin of the Seismological Society of America $\mathbf{8 0}$, 1951-1968

Harris, D. B. and T. Kværna (2010), Superresolution with seismic arrays using empirical matched field processing, Geophysical Journal International, 182, 1455-1477, doi:10.1111/j.1365246x.2010.04684.x

Kennett, B. L. N. (2002), The Seismic Wavefield - Volume 2. Interpretation of Seismograms on Regional and Global Scales, Cambridge University Press, Cambridge, UK. ISBN 9780521006651.

Koper, K. D., de Foy, B., and Benz, H. (2009), Composition and variation of noise recorded at the Yellowknife Seismic Array, 1991-2007, Journal of Geophysical Research 114 (B10), B10310, doi:10.1029/2009jb006307

Koper, K. D., Pyle, M. L., and Franks, J. M. (2003), Constraints on aspherical core structure from PKiKP-PcP differential travel times, Journal of Geophysical Research 108 (B3), 2168, doi:10.1029/2002jb001995

Kværna, T. and Doornbos, D. J. (1986), An integrated approach to slowness analysis with arrays and three-component stations, in NORSAR Scientific Report 2-1985/1986, Semiannual Technical Summary, 1 April - 30 September 1986, 60-69, NORSAR, Kjeller, Norway.

Kværna, T. and F. Ringdal (1992), Integrated array and three-component processing using a seismic microarray, Bulletin of the Seismological Society of America 82, 870-882

Kværna, T. and F. Ringdal (2013), Detection Capability of the Seismic Network of the International Monitoring System for the Comprehensive Nuclear-Test-Ban Treaty, Bulletin of the Seismological Society of America 103, 759-772, doi:10.1785/0120120248

Levander, A., E. D. Humphreys, G. Ekström, A. S. Meltzer, and P. M. Shearer (1999), Proposed project would give unprecedented look under North America, EOS Transactions, AGU, 80, 245-251, doi:10.1029/99eo00181

Okada, Y., K. Kasahara, S. Hori, K. Obara, S. Sekiguchi, H. Fujiwara, A. Yamamoto (2004), Recent progress of seismic observation networks in Japan - Hi-net, F-net, K-NET and KiK-net-, Earth Planets Space, 56 15-28, doi:10.1186/BF03353076

Romanowicz, B. and Giardini, D. (2001), The Future of Permanent Seismic Networks, Science, 293, 2000-2001, doi:10.1126/science.1061771 
Schweitzer, J. (2014), Seismometer Arrays, in Encyclopedia of Earthquake Engineering, Springer, ed.s M. Beer, I. A. Kougioumtzoglou, E. Patelli, I. S. Au, doi:10.1007/978-3-642-36197-5 191-1

Stump, B. W., Myung-Soon, J., Hayward, C., Jeong-Soo, J., Che, II-Young, Thomason, K., House, S. M., and McKenna, J. (2004), Small-Aperture Seismo-Acoustic Arrays: Design, Implementation, and Utilization, Bulletin of the Seismological Society of America 94, 220-236 doi:10.1785/0120020243

Vidale, J. E. (1986), Complex polarization analysis of particle motion, Bulletin of the Seismological Society of America 76, 1393-1405

Wessel, P. and W. H. F. Smith (1995), New version of the generic mapping tools released, EOS Transactions, American Geophysical Union 76, no. 33, 329, doi:10.1029/98eo00426. 